\title{
Challenges regarding the control of environmental sources of contamination in healthcare settings in low-and middle- income countries - a narrative review
}

Folasade T. Ogunsola ${ }^{1,2^{*}}$ (D) and Shaheen Mehtar ${ }^{3,2}$

\begin{abstract}
Background: Healthcare-associated infections (HAl) especially outbreaks of multi-drug-resistant organisms within hospitals are recognized as a major contributor to morbidity and mortality of hospitalized patients. The healthcare environment can act as an amplifier of HAl during outbreaks. The risk of acquiring HAl are 20 times higher in Lowand-middle-income countries.

The purpose of this article is to review the challenges associated with controlling environmental contamination in low and lower-middle income countries (LMIC), highlighting possible solutions.

Method: This is a narrative review. A literature search was carried out in Google scholar, PubMed, Science Direct, EBSCOHOST, CENGAGE, Scopus, ProQuest, Clinical Key and African journals online using the key words - Health care Associated Infections (HCAls) in LMICs, Challenges of HAls in LMIC, Challenges of Prevention and Control of HAls in LMICS, Environment of care and infection transmission, Contaminated environment and HAls.

Results: From the accessed databases, 1872 articles related to environmental sources of contamination in healthcare settings were found. Of these, only 530 articles focused on LMICs. However, only 186 articles met the inclusion criteria studies published in English, conducted between 2000 and 2019 and exploring environmental sources of contamination in LMIC healthcare settings). The sources of environmental contamination in healthcare are numerous and commonly associated with poor governance, Inadequate infrastructure, human capacity and inadequate funding. Low awareness exists at all levels as to the role of the environment in healthcare outcomes and may explain in part the low priority given for funding.

Conclusion: Leadership and trained personnel, both Infection prevention and control practitioners and cleaners are crucial
\end{abstract} to drive and sustain the process to reduce environmental contamination in healthcare environments.

Keywords: Challenges, Environment, Contamination, Infection control, Low-and-lower middle income

\footnotetext{
*Correspondence: sade.ogunsola@gmail.com

${ }^{1}$ College of Medicine, University of Lagos, Ishaga, Lagos PMB 12003, Nigeria

${ }^{2}$ Infection Control Africa Network, Cape Town, South Africa

Full list of author information is available at the end of the article
}

(C) The Author(s). 2020 Open Access This article is licensed under a Creative Commons Attribution 4.0 International License, which permits use, sharing, adaptation, distribution and reproduction in any medium or format, as long as you give appropriate credit to the original author(s) and the source, provide a link to the Creative Commons licence, and indicate if changes were made. The images or other third party material in this article are included in the article's Creative Commons licence, unless indicated otherwise in a credit line to the material. If material is not included in the article's Creative Commons licence and your intended use is not permitted by statutory regulation or exceeds the permitted use, you will need to obtain permission directly from the copyright holder. To view a copy of this licence, visit http://creativecommons.org/licenses/by/4.0/ The Creative Commons Public Domain Dedication waiver (http://creativecommons.org/publicdomain/zero/1.0/) applies to the data made available in this article, unless otherwise stated in a credit line to the data. 


\section{Introduction}

The hospital environment plays an important role in infection transmission particularly for multi-drug-resistant organisms (MDROs) which have the ability to persist in the healthcare environment $[1,2]$. This has led to increased recognition of the environment as an amplifier of healthcare associated infections (HAI) particularly during outbreaks of MDROs. The main goal of an infection prevention and control (IPC) program is to reduce risk of healthcare associated infections (HAI) and this includes the healthcare environment. However, the contribution of the healthcare environment in low to middle income countries (LMICs) is largely unknown. The stratification of income groups by The World Bank generally reflects the funding of healthcare budgets of individual countries. Thus, LMIC countries spend less on healthcare service provision and delivery with significant negative impact on clean and safe environments of care $[3,4]$.

\section{The significance of the environment in contamination}

The environment of care is the space around a patient or healthcare worker where direct or indirect contact occurs by those delivering healthcare. It comprises of three elements; the physical space or building used for providing patient care; equipment used in providing patient care or used within operational procedures of patient care; and people, including healthcare staff and visitors [5]. This physical space during in-patient care can be broadly categorized into 'high-touch' and 'low-touch' surfaces [6]. The former relates to frequently touched surfaces and therefore a higher risk of HAI transmission, while the latter relates to areas with minimal hand contact and therefore less likely to be a source of transmission [7]. The impact of the environment on infection rates has been demonstrated. When adequate environmental cleaning is lacking, the risk of infection increases when a patient is admitted immediately into an environment previously occupied by another patient infected by the same pathogen [2] thus highlighting the environment as a route of transmission of HAI. This has led to increased attention to environmental cleaning and cleanliness by healthcare systems, in a bid to strengthen IPC measures.

In 2003, the United States Centres for Disease Control and Prevention (CDC) emphasized the importance of implementing proper standards for environmental hygiene, including air, ventilation, water in the built environment [8]. A World Health Organisation (WHO) guideline on the core components of IPC (2016a) emphasized the importance of undertaking patient care activities in a hygienic environment in the prevention and control of HAIs and antimicrobial resistance (AMR). Important recommendations for Water Sanitation and Hygiene (WASH) services, infrastructure as well as the availability of appropriate infection prevention and control (IPC) materials and equipment are included in the implementation guide [9]. In 2019, the Infection Control Africa Network (ICAN), in collaboration with $\mathrm{CDC}$, produced a set of recommendations for LMICs on best practices in environmental cleaning in resource limited settings [10].

The environmental contaminants of healthcare spaces include skin squames, microorganisms and dust. Humans, especially those that are colonized, shed microorganisms into the environment particularly after physical activity $[11,12]$. The ability of microorganisms to survive in that environment will depend on temperature and humidity [13], the presence of organic matter capable of supporting the growth of pathogenic microorganisms [14] and the adequacy of cleaning. In healthcare, the rate of removal and dilution of airborne microorganisms, as well as surface characteristics and orientation (horizontal or vertical) have an effect on the survival of microbes [15]. Gram-positive organisms thrive in dry conditions and on dusty surfaces [16, 17], Gramnegative organisms generally persist in damp or moderately humid conditions [18] while fungi flourish not only in damp areas and on fibrous materials but can also survive on dusty surfaces [16]. Many pathogens can survive and retain their infectious potential in the environment for many hours, days or months [2, 19] therefore, in health systems where environmental cleaning is inadequate, the potential risk for HAI are considerably increased.

\section{Methods}

A narrative review of the challenges associated with control of environmental contamination was done. A literature search in Google scholar, PubMed, Science Direct, EBSCOHOST, CENGAGE, Scopus, ProQuest, Clinical Key and African journals online using the key words Health care Associated Infections (HCAIs) in LMICs, Challenges of HAIs in LMIC, Challenges of Prevention and Control of HAIs in LMICs, Environment of care and infection transmission, Contaminated environment and HAIs. Only articles published in English and between the years 2000-2019 were included. Literature focusing on children, adults, healthcare workers, and the hospital environment were reviewed. Abstracts and titles were evaluated for relevance. Guidelines on environmental cleaning, healthcare associated infections and infection control were also consulted. Practices of hygiene in hospital settings not focusing on LMICs were also used to make comparisons. Publications focusing on guidelines and practices of hospital-environment cleaning, disinfection of healthcare facilities and equipment, structural design guidelines and practices, environmental control systems, supply of portable water, and hospital 
waste management practices, were reviewed. The reviewed papers highlight the salient features of the challenges faced when implementing effective hospital hygiene and environmental cleaning and disinfection, control systems and practices in LMICs and proffers pragmatic solutions to prevent environmental contamination.

\section{Results}

From the accessed databases, 1872 articles related to environmental sources of contamination in healthcare settings were found. Of these, only 530 articles focused on LMICs. However, only 186 articles met the inclusion criteria studies published in English, conducted between 2000 and 2019 and exploring environmental sources of contamination in LMIC healthcare settings). The review of the relevant studies that met the stated inclusion criteria is presented in the following themes: Structure and Infrastructure; human capacity development; clinical and corporate governance; challenges implementing effective processes, procedures and protocols; and funding of environmental cleaning programme.

\section{Structure and infrastructure Structural design}

Healthcare facilities in LMIC's are often not purposebuilt and may have undergone extensive changes in layout and clinical activity over the years. Surfaces are often covered with materials that are not appropriate for ensuring safety. All health care work surface should be resistant to chemicals used daily for cleaning such as detergents (or disinfectants as appropriate) and can be easily wiped down [20] however some basic materials used in construction and surfaces in LMIC healthcare facilities do not meet international environmental hygiene safety standards $[20,21]$. More importantly, these surfaces become damaged due either to the overuse of chemical disinfectants such as chlorine, or a lack of resources for maintenance and repair, till it becomes impossible to maintain a clean and intact environment. The introduction of vaporized hydrogen peroxide or ultraviolet light, following terminal cleaning, have also been proposed as newer 'non-touch' (automated) decontamination technologies, however these are either unavailable or unaffordable in most LMICs.(20).

Other structural challenges are inadequate ventilation, inadequate numbers of wards, sinks, width of corridors and walkways, location of patient ablution facilities and inadequate sluice rooms. These often reducing accessibility to adequate cleaning. Ventilation, whether natural or mechanical [22], should be included in the design of purpose-built facilities or during renovations. While natural ventilation can remove and dilute airborne microbes such as M. tuberculosis [23], it is not a substitute for good environmental cleaning. High concentrations of airborne bacteria have been reported in densely populated locations such as the pharmacy, lobby and other areas with densities of 0.5 to $1 \mathrm{cfu}$ per $\mathrm{m}^{-2}$ of air in ward areas and these concentrations increased in proportion to the number of people in the room [24, 25] resulting in a heavier bioburden.

\section{Overcrowding in wards}

The ever-increasing demand on limited hospital beds has a major impact on environmental cleaning. The number of patients admitted in healthcare facilities in many LMICs often exceeds the number of available beds resulting in the sharing of beds or placing of patients on the floors in surrounding hallways and stairwells [26]. Overcrowding contributes to the inability to clean the environment satisfactorily and most importantly, beds are not vacated long enough to clean them properly, change linen and repair or discard torn mattresses. The increased workload affects more than clinical services- it also has an impact on services ablution facilities, toilets, water supply and power.

\section{Toilets}

In low resourced health facilities, patient toilets and sanitation facilities are of low priority and are often neglected when cleaning and maintenance programme are developed. In 2015, a WHO report highlighted that $20 \%$ of healthcare facilities globally had either no provision for toilets or were in inadequate numbers (between 1 and 3.5 toilets per facility) [27-29]. In a recent systematic review of WASH activities, the lack of cleanliness of toilets was a bigger problem than the absence of toilets; this was attributed to a lack of, or inadequate access to, clean water and had a significant negative impact on patient's assessment of care [30]. The impact of inadequate sanitation has a direct effect on increased transmission, particularly of MDROs (gram negative) and HAIs $[9,19]$.

\section{Misuse of hand wash sinks}

Sinks used for cleaning instruments were also used by surgeons and nurses to 'scrub' prior to surgery [31]. The WHO guidelines on decontamination and reprocessing of medical devices [32] outlines best practices including layout of a sterile services department or decontamination unit to ensure optimal workflow and cleanliness. It is concerning that the lack of physical separation of dirty and clean areas for decontamination results in mixing of clean and dirty medical devices and linen was reported [33] clearly suggesting that sterile services required review and training. It is noteworthy that the environment for reprocessing medical devices in $\mathrm{HI}$ is not documented as a potential source for HAI, however in LMICs it must always be taken into account when considering 
SSIs particularly because of inadequate cleaning of medical devices [33].

\section{Inadequate supply of potable water}

Effective environmental cleanliness of healthcare settings depends on the availability of safe and sufficient water for routine sanitation [21]. In a recent $\mathrm{WHO} / \mathrm{UNICEF}$ survey, $25 \%$ of health care facilities globally, lacked the basic services, (mainly located in LMICs) where constant water supply was either absent or limited [34]. The first- global WASH assessment of health care facilities was run in 54 LMICs and surveyed 66,101 facilities where $38 \%$ of them lacked access even to rudimentary levels of WASH. Large disparities also existed within countries and among facility types [35]. The Global Analysis and Assessment of Sanitation and Drinking water (GLAAS) survey report [36] revealed that only $25 \%$ of 86 countries that responded had a fully implemented plan or policy for drinking-water and sanitation in health care facilities. It was noted that countries with national plans had a greater proportion of facilities with water services, suggesting that national policies were essential for improving services. The absence of basic services has an adverse impact on the implementation of WASH services and IPC measures including environmental cleaning. Many outbreaks of HAIs in LMICs have been linked to contaminated water used during patient care especially maternal and child health and the cleaning of medical devices [37]. In India, Zambia and Tanzania, the lack of WASH facilities in delivery rooms has been commonly cited as a reason for preferring home delivery [30, 38, 39]. LMICs are increasingly encouraged to invest in water safety and ensure provision of clean water especially to healthcare facilities $[9,34]$. Where there is an inadequate or lack of water supply, boreholes may be sunk, or large reservoirs constructed to collect, and store rainwater and effective biocides used to clean the water storage tanks. It is important that such water is treated and tested regularly for microbiological growth at points-of-use to ensure that the supplied water is safe [40].

\section{Hospital waste management}

There are significant gaps in levels of compliance with recommended best practice for sustainable waste management and environmental cleanliness [41]. The lack of source segregation at point of use, colour coding up to unsafe transportation in open trucks to the end point disposal remains a major hazard and can lead to environmental contamination and occupational health dangers in healthcare settings. Final disposal of waste remains limited to crude incineration, open dumps and landfills with the potential for environmental pollution [42-45].

\section{Environmental cleaning}

In 2018 the International Society of Antimicrobial Chemotherapy (ISAC) published the results of an international survey with 110 replies from 23 countries [46]. Despite the existence of policies and training in 90, and $70 \%$ respectively methodology varied across the survey. ICAN, in collaboration with ISAC extended the survey to Africa. Seventy one replies were received from 15 African countries. Of interest were the differences in cleaning methods, chemicals and frequency (Fig. 1). Routine cleaning was either with water and detergent or disinfectant, while disinfectants were mainly used for terminal cleaning. Most (90\%) of the microorganisms present in visible dirt can be eliminated by routine cleaning using damp dusting, mopping with clean water and a detergent therefore routine disinfection is not indicated. Housekeeping staff must be trained regarding appropriate cleaning agents and the correct in use dilutions to avoid over-dilution of disinfectant solutions in a bid to stretch their use [47]. The newer methods proposed as 'non-touch' (automated) decontamination technologies, for terminal cleaning, such as vaporized hydrogen peroxide or ultraviolet light are either unavailable or unaffordable in most LMICs.

\section{Human capacity development}

Often there is no clear job description for healthcare workers and therefore there is a lack of accountability an essential part of good practice in healthcare. Healthcare workers continue to lack access to basic, practical education, information and effective training in IPC best practice especially for environmental hygiene, cleanliness and decontamination and there are few opportunities for learning $[48,49]$. In many facilities in Africa only 1-12\% of hospital staff responsible for sterile processing and standard environmental cleaning are trained $[33,50]$.

Training of cleaning and housekeeper staff, whether inhouse or outsourced, must be according to evidencebased guidelines and standard operating procedures laid out by the healthcare facility as part of the role of the IPC Committee. The training should be contextually appropriate (local languages and dialect) and use various methods (posters, videos). The training must competency-based which will require an examination and demonstration of correct practices [21, 51, 52]. Equally, the trainers should be qualified, and periodic proficiency evaluations of trainees should be undertaken to sustain effectiveness. ICAN is committed to improving IPC practices through structured training and knowledge transfer in Africa as part of its "From Cape to Cairo "education programme. Training for all levels of staff including both clinical and non-clinical staff, has to be competency based. Qualification for IPC professionals requires knowledge at Postgraduate Diploma level so that IPC support to healthcare 


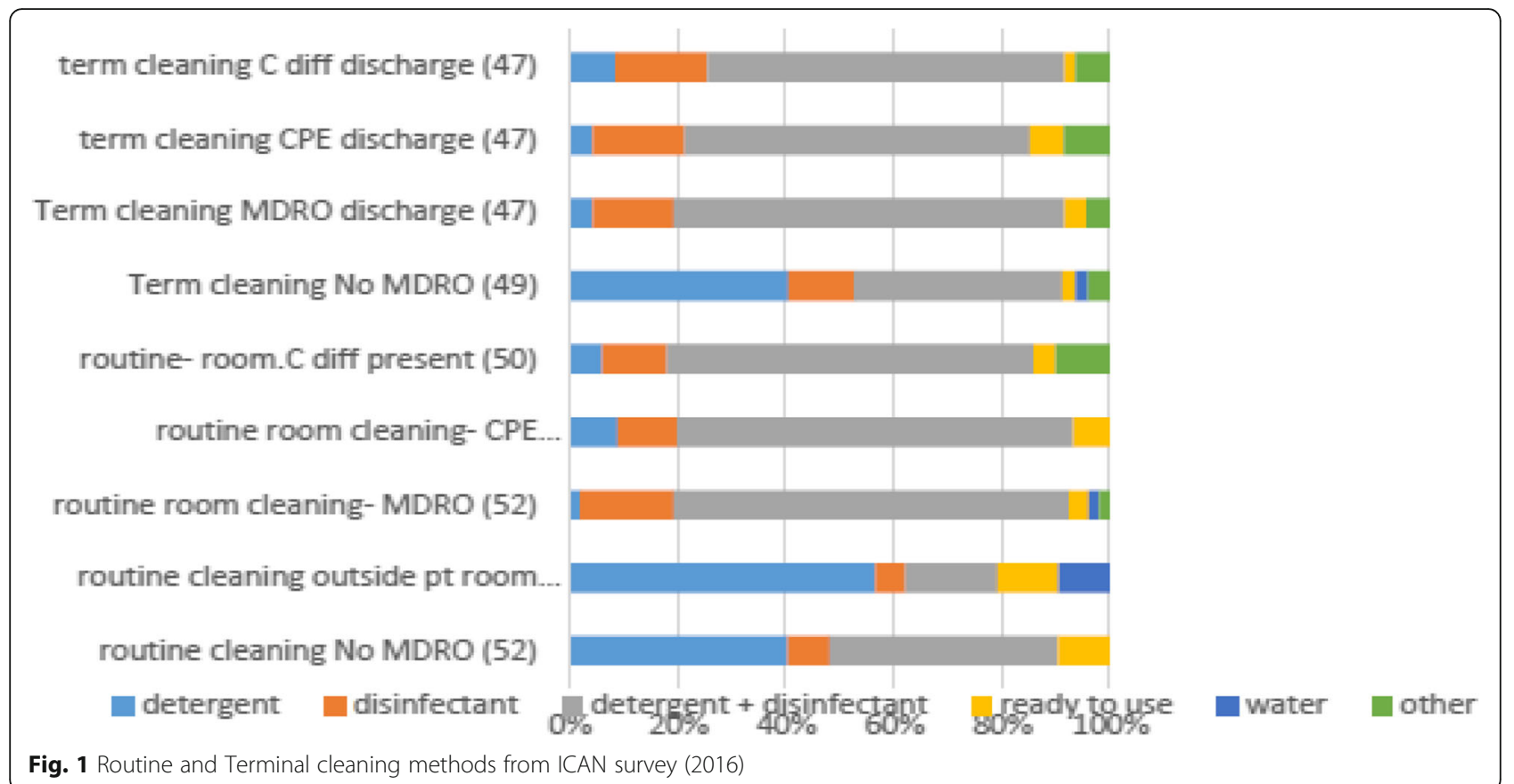

facilities is maximally effective including training and mentoring of cleaning staff.

\section{Clinical and corporate governance}

Unlike in high income countries, there is a paucity of reliable data to support cost effectiveness and impact studies of a clean environment in LMICs. This is due to limited publications, record-keeping and inadequacies in the follow-up of patients $[21,53]$. . However, the WHO and more recently CDC/ICAN (2019) has published several best practice documents, on environmental cleaning and disinfection.(10) Further the WHO has tools on surveillance of WASH infrastructures for cleaner environments with a focus on LMIC countries, which can be adopted and adapted to individual country needs [9]. Despite this, these guidelines are not consistently adhered to in many countries [21, 54]. Where they do exist, implementing practices for environmental decontamination has been ineffective. This is due in part to a lack of standardized protocols and efficient processes for evaluation [54]. In fact, national IPC polices and guidelines that are based on practical, low-cost, evidencebased strategies are yet to be developed for many LMICs $[11,54,55]$.

\section{Challenges implementing effective processes, procedures and protocols}

Implementing effective processes, procedures and protocols rests on a foundation of an effective organisational structure, availability of supplies, trained personnel and accountability. The procedures are usually concerned with general techniques, Cleaning of patient areas, terminal cleaning, management of spills of body fluids, cleaning patient-use items, cleaning toilets, critical and non-critical areas and assessments of cleanliness $[10$, 54-56].

In many countries both high and low income, cleaning is considered a menial job. In LMIC, these jobs are delegated to hospital attendants (lower job categories) with poorer educational levels who are usually untrained in cleaning protocols and practices resulting in poor outcomes and an increased risk of contamination [57]. Cleaners are often supervised by a nurse or cleaning supervisor who usually do not have specialised training on cleaning healthcare spaces. Standardized competency training and proper supervision including verification checks are essential and should be carried out routinely with the results being presented to the IPC Committee (if there is one) for further guidance. However, the cleaning is often not organised and written protocols and checklists are not available. This poor documentation and absence of written protocols and procedures cuts across all areas of IPC [55].

Best practices include the use of clean water and detergent for routine use [10] but where terminal cleaning is indicated after the discharge of an infectious patient, an appropriate disinfectant (either $70 \%$ alcohol without any other additions such as chlorhexidine, or $0.2-0.5 \%$ chlorine (for C. difficile) is to be applied on a cloth not sprayed after the surfaces have been thoroughly cleaned and dried [58]. Unavailability of appropriate materials for cleaning which are contextually appropriate is also a 
challenge in LMICs [44] but can be overcome by training cleaning and housekeeping staff on best practices [47]. Assessment of cleanliness is usually done visually in LMICs, a method that is no longer recommended [19]. Simple but efficient non-microbiological methods for reliable assessment of surface decontamination such as reflective surface markers and adenosine triphosphate analysis can be used [57, 59]. Microbiological methods where available should be used in consultation with the IPC team particularly during an outbreak investigation [60].

\section{Compliance with hand-hygiene procedures and protocols}

Hand hygiene facilities is an essential component in preventing environmental contamination and HAI. Hand hygiene $(\mathrm{HH})$ is, singularly, the most cost-effective IPC intervention yet suffers from a lack of practice and provision of adequate water supply. Alcohol based hand rub (ABHR) for hand hygiene has taken over from routine hand washing (except when hands are visibly contaminated) thereby reducing the need for water. In Nigeria, healthcare workers at a university teaching hospital paid attention to hand hygiene only when it appeared that there was an observable threat to their wellbeing [61]. Poor compliance with basic hand hygiene and hospital cleaning practices contribute to environmental contamination and can be addressed through provision of alcohol hand rub, facilities for handwash at convenient distances, reminders in the workplace, education and training [22].

\section{Funding of environmental cleaning programme}

More than $52 \%$ of healthcare financing in Africa relies heavily on personal payments for health services and is largely augmented by financial assistance from bilateral and multilateral donors [62]. Budgetary allocation for the prevention of HAIs do not exist [63] and modern environmental decontamination interventions are not regarded as urgent in resource-poor settings. A lack of political will is a major impediment to encourage government funding and involvement in sanitation and hygiene programs [64], especially if there is a lack of accountability and motivation around funding sanitation and hygiene programs [65]. In order to address the issue of inadequate funding particularly for environmental cleanliness in hospital facilities, it is important to promote and encourage the objectives of WASH in government planning and budgeting [35]. This can be achieved through lobbying government officials as well as other relevant stakeholders [66]. Although globally, governments have increased allocation of national funds and spending for universal WASH in schools and health care facilities [34, 67], there remain significant gaps between plans and available budgets within many LMICs, with
$80 \%$ of countries reporting that they lack sufficient funds to dedicate for WASH [68]. The commitment made by Heads of State in the African Union to allocate 15\% of their respective national budgets to health at the Abuja Declaration of 2001 [69] is yet to be implemented. Limited funding is an enduring challenge in LMICs with a high dependence on donors whose policies may not always be in alignment with the national priorities. Systems need to be established to ensure the judicious, conscientious and rational use of funds allocated for improvements and new developments in environmental decontamination [70]. It is imperative for LMICs to explore new and sustainable ways of health funding.

\section{Discussion}

Evidence supports the importance of a clean environment essential for driving down HAIs. The burden of environmental contamination is greater in low-resource settings and the challenges outlined in this review involve structure, process and outcome that exist at various system levels.

The lack of clinical governance, effective implementation strategies, guidelines and standards and most particularly funding leaves issues of environmental sanitation and hygiene low on the priority list. Where funds are available these are usually redirected for other purposes. Sadly, the cost of revising the current infrastructure in most LMICs is formidable and therefore has been side-lined or put on the back burner. Finally, the processes and administrative commitment to tackle and improve the WASH infrastructure is not in place. This could be either due to a lack of knowledge, financial resources or simply because it is of lower priority. The importance of the environment in the transmission of HAI is well documented. It is also evident that it is not just an LMIC concern and that major outbreaks with MDRO also occur in high income countries. So, the question is, where does this accountability lie? And how does it translate to practice? The answer lies within the healthcare systems. The challenges relating to environmental contamination in healthcare settings for LMICs are related to weak health systems that have been sustained by the lack of political will that manifests as inadequate governance, low accountability, inadequate allocation of resources, paucity of data relevant to decision-making, inadequately trained human resources, and inadequate infrastructure [4].

The challenges of environmental contamination therefore need to be addressed using a multi modal approach [71] and requires input from industries not traditionally associated with health-care delivery and service provision. The multimodal strategy builds on theories of change and is made up of several components that should be implemented in an integrated way to improve 
outcome taking into account the local context. This will include components that address the infrastructure, the supplies, the knowledge, attitude and practice of personnel, the workplace governance and the plans for sustainability and quality assurance.

The solutions will therefore include changes to infrastructure such as covering porous surfaces with hardwearing non- porous linoleum which can be found in many markets in developing countries and are relatively inexpensive, raising awareness of administrators about the dangers of unclean environments, training of all stakeholders involved in the cleaning process and governance including end users. Increased awareness of the importance of environmental hygiene by the facility administration may lead to improved organization of processes, support for staff and increased allocation of funds.

What is often required to start the process of change is a committed individual, a champion. This individual needs to be not only knowledgeable about the task but also the healthcare system within which he works. He must be passionate enough to bring his creativity to bear on surmounting the many challenges that are present in the healthcare space. The champion must be able to motivate others to commit to the time, activities and effort required to change their circumstances. Champions can be described as sociological citizens in the workplace bringing their diligence to bear on improving outcomes [72]. In some settings it has been the infection control officer, a link-nurse or the environmental supervisor.

The need to adopt appropriate technology and country-specific strategies in order to achieve the common goal of preventing environmental contamination, HAI and AMR is also recommended. Strategic goals that support the implementation of respective national standards in ways that reflect local and country-specific conditions should be established [73]. Implementation tools to help countries achieve their goals are recommended and have been developed by the WHO [74]. Policies will provide a framework for configuration, utilization and quality management strategies to address the various challenges resulting from environmental contamination. Leadership is crucial and an increase in political awareness can lead to the much needed changes to improve outcomes [51] such as more trained IPC professionals including cleaning staff that are required to drive the process of reducing environmental contamination by working with other healthcare workers to develop policies, set standards and ensure effective implementation of processes, practices and training programs.

\section{Conclusion}

The challenges encountered in the control of environmental contamination in Low and middle income countries though mostly similar to those in high income countries are significantly more pronounced as a result of the poor infrastructure, lack of prioritisation, inadequate numbers of trained personnel and poor funding. The evidence showing the role of a clean environment in reducing the rates of Healthcare associated infections is compelling and has been encapsulated in the core components of an effective infection control program. It is evident that the challenges identified are already recognised by the countries and in many, some effort is already being made. However, more needs to be done and requires committed leadership to provide the framework for and drive the change to provide a safe environment for healthcare.

\section{Acknowledgements \\ Mr. Patrick Okonji for his assistance in literature search.}

\section{Authors' contributions}

FO wrote the first draft and contributed to the final article. SM reviewed the first draft and contributed to the final article. Both authors read and

approved the final manuscript.

\section{Funding}

No funding was obtained.

\section{Availability of data and materials}

"Data sharing not applicable to this article as no datasets were generated or analysed during the current study.

\section{Ethics approval}

Not Applicable.

\section{Consent for publication}

Not Applicable.

\section{Competing interests}

"The authors declare that they have no competing interests."

\section{Author details}

${ }^{1}$ College of Medicine, University of Lagos, Ishaga, Lagos PMB 12003, Nigeria. ${ }^{2}$ Infection Control Africa Network, Cape Town, South Africa. ${ }^{3}$ Stellenbosch University Cape Town, Cape Town, South Africa.

Received: 12 September 2019 Accepted: 1 June 2020

Published online: 09 June 2020

\section{References}

1. Fletcher S. Understanding the contribution of environmental factors in the spread of antimicrobial resistance. Environ Health Prev Med. 2015;20:243.

2. Kramer A, Assadian O. Survival of microorganisms on inanimate surfaces. In use of Biocidal surfaces for reduction of healthcare acquired infections 2014: (pp. 7-26). Springer. Cham.

3. World Bank. World Bank Country and Lending groups. 2019. Retrieved from:https://datahelpdesk.worldbank.org/knowledgebase/articles/906519world-bank-countryand-lending-groups.

4. Bardossy AC, Zervos J, Zervos M. Preventing hospital-acquired infections in low income and middle-income countries: impact, gaps, and opportunities. Infect Dis Clin. 2016;30:805-18.

5. Reiling J, Hughes RG, Murphy MR. The impact of facility design on patient safety. Inpatient safety and quality: an evidence-based handbook for nurses 2008 Apr. Agency for Healthcare Research and Quality (US).

6. Huslage K, Rutala WA, Sickbert-Bennett E, Weber DJ. A quantitative approach to defining "high-touch" surfaces in hospitals. Infection Control \& Hospital Epidemiology. 2010;31:850-3.

7. Huslage K, Rutala WA, Gergen MF, Sickbert-Bennett EE, Weber DJ. Microbial assessment of high-, medium-, and low-touch hospital room surfaces. Infection Control \& Hospital Epidemiology. 2013;34:211-2. 
8. CDC. Centre for Disease Control: Environmental Infection Control Guidelines. 2003. Retrieved from: https://www.cdc.gov/infectioncontrol/ guidelines/environmental/index.html (Date: 13/06/2019).

9. World Health Organization. Guidelines on core components of infection prevention and control programmes at the national and acute health care facility level. World Health Organization; 2016. Available online: https://apps. who.int/iris/bitstream/handle/10665/251730/9789241549929-eng.pdf.

10. CDC and ICAN. Best Practices for Environmental Cleaning in Healthcare Facilities in Resource-Limited Settings. Atlanta, GA: US Department of Health and Human Services, CDC; Cape Town, South Africa: Infection Control Africa Network; 2019. Available at: http://www.icanetwork.co.za/icanguideline2019/ and https://www.cdc.gov/hai/prevent/resource-limited/environmentalcleaning.html.

11. Fletcher, M. (1991). The physiological activity of bacteria attached to solid surfaces. In Advances in microbial physiology (Vol. 32, pp. 53-85). Academic press.

12. Neely AN, Sittig DF. Basic microbiologic and infection control information to reduce the potential transmission of pathogens to patients via computer hardware. J Am Med Inform Assoc. 2002;9:500-8.

13. Evans J, Russell SL, James C, Corry J. Microbial contamination of food refrigeration equipment. In 13th World Congress of Food Science \& Technology 2006. (pp. 800-800).

14. Tang JW. The effect of environmental parameters on the survival of airborne infectious agents. J R Soc Interface. 2009;6(suppl 6):S737-46.

15. Taylor J, man Lai K, Davies M, Clifton D, Ridley I, Biddulph P. Flood management: prediction of microbial contamination in large-scale floods in urban environments. Environment international. 2011; 37:1019-29.

16. Khelissa SO, Abdallah M, Jama C, Faille C, Chihib NE. Bacterial contamination and biofilm formation on abiotic surfaces and strategies to overcome their persistence. J Mater Environ Sci. 2017;8:3326-46.

17. Yassin MF, Almouqatea S. Assessment of airborne bacteria and fungi in an indoor and outdoor environment. International Journal of Environmental Science \& Technology. 2010;7:535-44.

18. Gould DI, Chamberlain AN. Gram-negative bacteria. The challenge of preventing cross infection in hospital wards: a review of the literature. J Clin Nurs. 1994:3:339-45.

19. Dancer SJ. Controlling hospital-acquired infection: focus on the role of the environment and new technologies for decontamination. Clin Microbiol Rev. 2014;27:665-90.

20. Adams J, Bartram J, Chartier Y, editors. Essential environmental health standards in health care. World Health Organization; 2008. Retrieved from: https://www.who.int/water_sanitation_health/hygiene/settings/ehs_health_ care.pdf.pdf.

21. Cronk R, Bartram J. Environmental conditions in health care facilities in lowand middle income countries: coverage and inequalities. Int J Hyg Environ Health. 2018;221:409-22.

22. Chinn RY, Sehulster L. Guidelines for environmental infection control in health-care facilities; recommendations of CDC and Healthcare Infection Control Practices Advisory Committee (HICPAC). MMWR. 2003; 52(RR-10):142 https://www.cdc.gov/mmwr/preview/mmwrhtml//r5210a1.htm.

23. Obbard JP, Fang LS. Airborne concentrations of bacteria in a hospital environment in Singapore. Water Air Soil Pollut. 2003;144:333-41.

24. Rimi NA, Sultana R, Luby SP, Islam MS, Uddin M, Hossain MJ, Zaman RU, Nahar N, Gurley ES. Infrastructure and contamination of the physical environment in three Bangladeshi hospitals: putting infection control into context. PLoS One. 2014;9:e89085

25. World Health Organization (WHO). Guidelines on Hand Hygiene in Health Care: First Global Patient Safety Challenge Clean Care Is Safer Care World Health. Organization, 2009.Geneva.

26. Shahida SM, Islam A, Dey BR, Islam F, Venkatesh K, Goodman A. Hospital acquired infections in low and middle income countries: root cause analysis and the development of infection control practices in Bangladesh. Open Journal of Obstetrics and Gynecology. 2016;6:28.

27. Ezegwui IR, Okoye Ol, Aghaji AE, Okoye O, Oguego N. Patients' satisfaction with eye care services in a Nigerian teaching hospital. Niger J Clin Pract. 2014;17:585-8.

28. Khamis K, Njau B. Patients' level of satisfaction on quality of health care at Mwananyamala hospital in Dar Es Salaam. Tanzania BMC Health Serv Res. 2014;14:400

29. Steinmann P, Bratschi MW, Lele P, et al. Availability and satisfactoriness of latrines and hand washing stations in health facilities, and role in health seeking behavior of women: evidence from rural Pune district, India. Journal of Water, Sanitation and Hygiene for Development. 2015;5:474-82.

30. Bouzid M, Cumming O, Hunter PR. What is the impact of water sanitation and hygiene in healthcare facilities on care seeking behaviour and patient satisfaction? A systematic review of the evidence from low-income and middle-income countries BMJ global health. 2018;3:648.

31. WHO: Global Guidelines for the Prevention of Surgical Site Infection. World Health Organization, 2016b. Retrieved from: https:/apps.who.int/iris/ bitstream/handle/10665/250680/9789241549882-eng.pdf?sequence $=8$.

32. WHO. Decontamination and Reprocessing of Medical Devices in Healthcare Facilities. World Health Organization.2016. Retrieved from https:/apps.who.int/ iris/bitstream/handle/10665/250232/9789241549851-eng.pdf?sequence=1.

33. Fast O, Fast C, Fast D, Veltjens S, Salami Z, White MC. Limited sterile processing capabilities for safe surgery in low-income and middle-income countries: experience in the republic of Congo. Madagascar and Benin BMJ Global Health. 2017;2(Suppl 4):428.

34. Forrester JA, Powell BL, Forrester JD, Fast C, Weiser TG. Surgical instrument reprocessing in resource-constrained countries: a scoping review of existing methods, policies, and barriers. Surg Infect. 2018:19(6):593-602

35. WHO \& UNICEF. World Health Organization, United Nations' Children's Fund. Water,Sanitation and Hygiene in Health Care Facilities - Status in Low- and Middle-Income Countries and Way Forward; 2015. pp. 1-13.

36. World Health Organization. Investing in water and sanitation: increasing access,reducing inequalities: GLAAS 2014 findings-highlights for the Eastern Mediterranean Region (No. WHO/FWC/WSH/15.08). World Health Organization.2015.

37. Huttinger A, Dreibelbis R, Kayigamba F, Ngabo F, Mfura L, Merryweather B, Cardon A, Moe C. Water, sanitation and hygiene infrastructure and quality in rural healthcare facilities in Rwanda. BMC Health Serv Res. 2017;17:517.

38. MacKeith N, Chinganya OJ, Ahmed Y, et al. Zambian women's experiences of urban maternity care: results from a community survey in Lusaka. Afr J Reprod Health. 2003;7:92-102.

39. Mbwele B, Ide NL, Reddy E, et al. Quality of neonatal healthcare in Kilimanjaro region, Northeast Tanzania: learning from mothers' experiences. BMC Pediatr. 2013;13:68

40. Mehtar S. and Bearman G (2018). Guide to infection control in the hospital. Retrieved online: https://www.isid.org/wpcontent/uploads/2018/07/ISID_ InfectionGuide Chapter19.pdf.

41. United Nations Environment Program (UNEP)/SBC and World Health Organization (UNEP/WHO). Preparation of National Healthcare Waste Management Plans in Sub-Saharan countries - Guidance Manual. WHO document production services, Geneva,Switzerland.

42. Hachicha W, Mellouli M, Khemakhem M, Chabchoub H. Routing system for infectious healthcare-waste transportation in Tunisia: a case study. Environ Eng Manag J. 2014;13:21-9.

43. Olaifa A, Govender RD, Ross AJ. Knowledge, attitudes and practices of healthcare workers about healthcare waste management at a district hospital in KwaZulu-Natal. S Afr Fam Pract. 2018;60:137-45.

44. Ali M, Wang W, Chaudhry N, Geng Y. Hospital waste management in developing countries: A mini review. Waste Management \& Research. 2017; 35:581-92.

45. Awomeso JA, Taiwo AM, Gbadebo AM, Arimoro AO. Waste disposal and pollution management in urban areas: a workable remedy for the environment in developing countries. Am J Environ Sci. 2010;6:26-32.

46. Kenters N, Gottlieb T, Hopman J, Mehtar S, Schweizer ML, Tartari E, Huijskens EG, Voss A. An international survey of cleaning and disinfection practices in the healthcare environment. J Hosp Infect. 2018;100:236-41.

47. Boyce JM. Modern technologies for improving cleaning and disinfection of environmental surfaces in hospitals. Antimicrobial Resistance \& Infection Control. 2016; 5:10.

48. Pakenham-Walsh N, Bukachi F. Information needs of health care workers in developing countries: a literature review with a focus on Africa. Human resources for health; 2009:7:30.

49. Peters A, Otter J, Moldovan A, Parneix P, Voss A, Pittet D. Keeping hospitals clean and safe without breaking the bank; summary of the healthcare cleaning forum 2018. Retrieved from: https://aricjournal.biomedcentral.com/ articles/10.1186/s13756-018-0420-3.

50. Akter N, Chowdhury AM, Kazi NM. Hospital waste disposal in Bangladesh with special reference to Dhaka City and its environmental evaluation. Special Publication. 1999. Feb 87. http://citeseerx.ist.psu.edu/viewdoc/ download?doi=10.1.1.530.8191\&rep=rep1\&type=pdf. 
51. Allegranzi B, Pittet D. Healthcare-associated infection in developing countries: simple solutions to meet complex challenges. Infection Control \& Hospital Epidemiology. 2007;28:1323-7.

52. Olans RN, Olans RD, DeMaria A Jr. The critical role of the staff nurse in antimicrobial stewardship - unrecognized, but already there. Clin Infect Dis. 2015;62:84-9.

53. Ahoyo TA, Bankolé HS, Adéoti FM, Gbohoun AA, Assavèdo S, AmoussouGuénou M, Kindé-Gazard DA, Pittet D. Prevalence of nosocomial infections and anti-infective therapy in Benin: results of the first nationwide survey in 2012. Antimicrob Resist Infect Control. 2014;3:17

54. Weinshel K, Dramowski A, Hajdu Á, Jacob S, Khanal B, Zoltán M, Mougkou K, Phukan C, Staneloni MI. Singh N. Gap analysis of infection control practices in low-and middleincome countries infection control \& hospital epidemiology. 2015;36:1208-14.

55. Hussein J, Mavalankar DV, Sharma S, D'Ambruoso L. A review of health system infection control measures in developing countries: what can be learned to reduce maternal mortality. Glob Health. 2011;7:14.

56. Han JH, Sullivan N, Leas BF, Pegues DA, Kaczmarek JL, Umscheid CA. Cleaning hospital room surfaces to prevent health care-associated infections. A technical brief. Ann Intern Med. 2015;163:598-607.

57. Kaur K, Arora P, Biswal M. Hospital Surface Disinfection: Need, Gaps, Challenges and Management for "Basin and Mop" Method. J Hosp Med Manage; 2018: 4:10.

58. World Health Organization, Essential Environmental Health Standards in Health Care, WHO, Geneva, 2008. https://www.who.int/water_sanitation_ health/publications/ehs_hc/en/.

59. Sherlock O, O'Connell N, Creamer E, Humphreys $\mathrm{H}$. Is it really clean? An evaluation of the efficacy of four methods for determining hospital cleanliness. J Hosp Infect. 2009;72:140-6.

60. CDC. Environmental Sampling or Measurement. 2008. Retrieved from: https://www.ciriscience.org/a_85-Environmental-Sampling-or-Measurement.

61. Shobowale EO, Adegunle B, Onyedibe K. An assessment of hand hygiene practices of healthcare workers of a semi-urban teaching hospital using the five moments of hand hygiene. Nigerian medical journal: journal of the Nigeria Medical Association. 2016;57:150.

62. McIntyre D, Obse AG, Barasa EW, Ataguba JE. Challenges in financing universal health coverage in sub-Saharan Africa. In Oxford Research Encyclopedia of Economics and Finance 2018 May 24. Retrieved from [https://oxfordre.com/economics/abstract/10.1093/acrefore/9780190625979. 001.0001/a crefore-9780190625979-e-28.

63. Raka L. Prevention and control of hospital-related infections in low and middle income countries. Open Infect Dis J. 2010;4:125-31.

64. Jones M, Whitfield A, Thomas S, Gower S, Michael R. Educational innovation for infection control in Tanzania: bridging the policy to practice gap. J Infect Prev. 2014;15:94-8.

65. Asian Development Bank. Independent Evaluation Department Impact of Rural Water Supply and Sanitation in Punjab, Pakistan. 2017. [accessed on 15th July 2019]; Available online: https://www.adb.org/sites/default/files/ evaluationdocument/35047/files/ies-pak-2009-26.pdf.

66. Annamraju S, Calaguas B, Gutierrez E. Financing water and sanitation. Key issues in increasing resources to the Sector, Water Aid briefing paper. 2001:2-30

67. McGinnis S, McKeon T, Desai R, Ejelonu A, Laskowski S, Murphy H. A systematic review: costing and financing of water, sanitation, and hygiene (WASH) in schools. Int J Environ Res Public Health. 2017;14:442.

68. World Health Organization. Investing in water and sanitation: increasing access,reducing inequalities: GLAAS 2014 findings-highlights for the Eastern Mediterranean Region. World Health Organization; 2015.

69. WHO. The Abuja Declaration. 2001. Retrieved from:https://www.who.int/ healthsystems/publications/Abuja10.pdf.

70. World health report. Health systems financing - the path to universal coverage. Geneva: World Health Organization; 2010.

71. Guidelines on core components of infection prevention and control programmes at the national and acute health care facility level. Geneva: World Health Organization; 2016. Licence: CC BY-NC-SA 3.0 IGO.

72. Corbett A, Travaglia J, Braithwaite J. The role of individual diligence in improving safety", J Health Org and Mgt, 2011; 25:247-260. doi.org/10.1108/ 14777261111143518.

73. Storr J, Twyman A, Zingg W, Damani N, Kilpatrick C, Reilly J, Price L, Egger M, Grayson ML, Kelley E, Allegranzi B. Core components for effective infection prevention and control programmes: new WHO evidence-based recommendations. Antimicrobial Resistance \& Infection Control. 2017;6:6.
74. World Health Organization. WHO guidelines on hand hygiene in health care: first global patient safety challenge. 2017. Retrieved from:http://apps. who.int/iris/bitstream/10665/44102/1/9789241597906_eng.pdf.

\section{Publisher's Note}

Springer Nature remains neutral with regard to jurisdictional claims in published maps and institutional affiliations.
Ready to submit your research? Choose BMC and benefit from:

- fast, convenient online submission

- thorough peer review by experienced researchers in your field

- rapid publication on acceptance

- support for research data, including large and complex data types

- gold Open Access which fosters wider collaboration and increased citations

- maximum visibility for your research: over $100 \mathrm{M}$ website views per year

At $\mathrm{BMC}$, research is always in progress.

Learn more biomedcentral.com/submissions 